\title{
ARMAZENAMENTO EM ATMOSFERA MODIFICADA E CONTROLADA DE BANANA 'PRATA' COM ABSORÇÃO DE ETILENO
}

\author{
Modified and controlled atmosphere storage of 'Prata' banana with ethylene scrubbing
}

\author{
Auri Brackmann', Cristiano André Steffens ${ }^{2}$, Ivan Sestari³, \\ Daniel Alexandre Neuwald ${ }^{4}$, Ricardo Fabiano Hettwer Giehl ${ }^{5}$
}

\begin{abstract}
RESUMO
Foram conduzidos dois experimentos com o objetivo de avaliar o efeito da absorção do etileno e de pressões parciais de $\mathrm{O}_{2}$ e $\mathrm{CO}_{2}$ sobre a qualidade da banana 'Prata'. Os tratamentos no experimento 1 foram: AR (armazenamento refrigerado); AR + AE (absorção de etileno); e AM (atmosfera modificada) + AE. No experimento 2 os tratamentos foram: AR; AR + AE; AM + AE; 21,0 kPa $\mathrm{O}_{2}+3,0 \mathrm{kPaCO}+\mathrm{AE} ; 21,0 \mathrm{kPa} \mathrm{O}+4,5 \mathrm{kPa} \mathrm{CO}+\mathrm{AE} ; 21,0 \mathrm{kPa} \mathrm{O}+6,0 \mathrm{kPa} \mathrm{CO}+\mathrm{RA} ; 21,0 \mathrm{kPa} \mathrm{O}+4,5 \mathrm{kPa} \mathrm{CO} ;$ e 2,0 kPa $\mathrm{O}_{2}+4,5 \mathrm{kPa} \mathrm{CO}+\mathrm{AE}$. As temperaturas de armazenamento foram $25^{\circ} \mathrm{C}$ e $12^{\circ} \mathrm{C}$ para os experimentos 1 e 2, respectivamente. Para o armazenamento em atmosfera modificada foram utilizados filmes de polietileno de baixa densidade, com espessura de $16 \mu$. No experimento 1, a absorção de etileno proporcionou frutos com maior firmeza de polpa e menor escurecimento da casca. A AM+AE proporcionou frutos com cor da epiderme mais verde. No experimento 2, verificou-se que todos tratamentos em atmosfera controlada com absorção de etileno apresentaram cor da casca mais verde e menor escurecimento da casca. A banana 'Prata' pode ser armazenada em atmosfera modificada durante 14 e 21 dias a $25^{\circ} \mathrm{C} \mathrm{e} 12^{\circ} \mathrm{C}$, respectivamente, e por 28 dias em atmosfera controlada a $12^{\circ} \mathrm{C}$, sempre com absorção do etileno.
\end{abstract}

Termos para indexação: Pós-colheita, amadurecimento, Musa sp.

\begin{abstract}
Two experiments were carried out with the objective to evaluate the effect of storage conditions and ethylene scrubbing on the quality of 'Prata' bananas. The treatments of experiment 1 were: cold storage (CS); CS + ES (ethylene scrubbing) and MA (modified atmosphere) $+\mathrm{ES}$. In experiment 2 treatments were: $\mathrm{CS} ; \mathrm{CS}+\mathrm{ES} ; \mathrm{MA}+\mathrm{ES} ; 21 \mathrm{kPa} \mathrm{O}_{2}+3 \mathrm{kPa} \mathrm{CO}_{2}+\mathrm{ES} ; 21 \mathrm{kPa} \mathrm{O}+$ $4.5 \mathrm{kPa} \mathrm{CO}+\mathrm{ES} ; 21 \mathrm{kPa} \mathrm{O}_{2}+6 \mathrm{kPa} \mathrm{CO}_{2}+\mathrm{ES} ; 21 \mathrm{kPa} \mathrm{O}+4.5 \mathrm{kPa} \mathrm{CO}_{2}$; and $2 \mathrm{kPa} \mathrm{O}_{2}+4.5 \mathrm{kPa} \mathrm{CO}_{2}+\mathrm{ES}$. The storage temperatures were $25^{\circ} \mathrm{C}$ and $12^{\circ} \mathrm{C}$ for the experiments 1 and 2, respectively. In experiment 1, ethylene scrubbing maintained higher flesh firmness and lower skin browning. MA+ES maintained greener peel color. In experiment 2, all treatments of controlled atmosphere with ethylene scrubbing resulted in greener peel color and less skin browning. In conclusion, with ethylene scrubbing, 'Prata' bananas can be stored in modified atmosphere for 14 or 21 days at $25^{\circ} \mathrm{C}$ or $12^{\circ} \mathrm{C}$, respectively, or 28 days in controlled atmosphere at $12^{\circ} \mathrm{C}$.
\end{abstract}

Index terms: Postharvest, ripening, Musa sp.

(Recebido para publicação em 2 de março de 2005 e aprovado em 23 de fevereiro de 2006)

\section{INTRODUÇÃO}

A banana é um fruto climatérico de vida pós-colheita relativamente curta e que apresenta mudanças acentuadas durante o amadurecimento. Por isso, o transporte de bananas a mercados mais distantes, na busca de um maior valor pelo produto, exige técnicas que evitam o amadurecimento rápido e o surgimento do escurecimento da casca, principalmente em regiões de clima quente.

O uso da atmosfera controlada (AC) é uma técnica muito utilizada na América Central para o transporte de bananas para a América do Norte e Europa (MADRID \& LOPEZ-LEE, 1996). Frutos transportados em AC apresentam retardamento da perda da cor verde na casca, maior firmeza de polpa e menor taxa respiratória e maior teor de sólidos solúveis totais (ELYATEM et al., 1994; MADRID \& LOPEZ-LEE, 1996). Porém, o transporte em atmosfera controlada exige uma estrutura com mais equipamentos e de custo mais elevado.

A atmosfera modificada é uma tecnologia bastante versátil e aplicável para vários tipos de frutos e vegetais, sendo relativamente simples e de baixo custo (JIANG et al., 1999). Estes mesmos autores afirmam que o período de armazenamento de bananas em temperatura ambiente pode ser semelhante ao do armazenamento refrigerado, desde que os frutos estejam embalados em filmes de polietileno com permanganato de potássio para absorver o etileno. Entretanto, Antoniali et al. (1996) não verificaram eficiência

1Engenheiro Agrônomo, Dr., Professor do Departamento de Fitotecnia - UFSM - brackman@ccr.ufsm.br

2Engenheiro Agrônomo, Dr., Professor do Departamento de Fitotecnia - UDESC - cristianosteffens@bol.com.br

${ }^{3}$ Engenheiro Agrônomo, Aluno do Programa de Pós-Graduação em Agronomia da UFSM - Bolsista CNPq - isestari@bol.com.br

${ }^{4}$ Engenheiro Agrônomo, Mestre, Aluno do Programa de Pós-Graduação em Agronomia da UFSM - Bolsista da CAPES - daneuwald@bol.com.br

${ }^{5}$ Engenheiro Agrônomo, Aluno do Programa de Pós-Graduação em Agronomia da UFSM Bolsista CNPq - Universidade Fedral de Santa Maria - $97105-900$ -

Santa Maria, RS - hetgiehl@yahoo.com.br 
da utilização de embalagem plástica confeccionada com permanganato de potássio na conservação pós-colheita de banana 'Nanicão'.

Desta forma, buscou-se com este trabalho, avaliar a eficiência da absorção de etileno e da utilização da atmosfera modificada e controlada na conservação da qualidade da banana 'Prata'.

\section{MATERIAL E MÉTODOS}

Foram conduzidos dois experimentos no Núcleo de Pesquisa em Pós-Colheita (NPP) do Departamento de Fitotecnia da Universidade Federal de Santa Maria, RS. Foram utilizados frutos da cultivar Prata, provenientes de um bananal comercial do município de Janaúba, MG. As bananas, após colhidas, foram transportadas a Porto Alegre por via aérea e de Porto Alegre à Santa Maria por transporte rodoviário, sendo que entre a colheita e o armazenamento dos frutos transcorreu um dia.

No experimento 1 , conduzido em $25^{\circ} \mathrm{C}$, os tratamentos consistiram nas seguintes condições de armazenamento: AR (armazenamento refrigerado), $\mathrm{AR}+\mathrm{AE}$ (absorção de etileno) e AM (atmosfera modificada) + AE. Para o armazenamento em atmosfera modificada foram utilizados filmes de polietileno de baixa densidade com espessura de 16 micra. Com o avanço do período de armazenamento as embalagens expostas à temperatura de $12^{\circ} \mathrm{C}$ e $25^{\circ} \mathrm{C}$ sofreram 10 e 50 microperfurações de $0,7 \mathrm{~mm}$ de diâmetro, respectivamente. Estas microperfurações foram feitas quando o $\mathrm{CO}_{2}$ superava os $7,0 \mathrm{kPa}$, cuja finalidade foi de possibilitar uma maior troca gasosa entre o interior da embalagem e o meio externo. No experimento 2, conduzido em $12^{\circ} \mathrm{C}$, os tratamentos utilizados foram: $\mathrm{AR}$ $(21,0 \mathrm{kPa} \mathrm{O}) ; \mathrm{AR}+\mathrm{AE} ; \mathrm{AM}+\mathrm{AE} ; \mathrm{AR}+3,0 \mathrm{kPa} \mathrm{CO}+\mathrm{AE}$; $\mathrm{AR}+4,5 \mathrm{kPa} \mathrm{CO}_{2}+\mathrm{AE} ; \mathrm{AR}+6,0 \mathrm{kPa} \mathrm{CO}+\mathrm{AE} ; \mathrm{AR}+4,5$ $\mathrm{kPa} \mathrm{CO}_{2}$; e 2,0 $\mathrm{kPa} \mathrm{O}_{2}+4,5 \mathrm{kPa} \mathrm{CO}_{2}+\mathrm{AE}$. O delineamento experimental utilizado foi o inteiramente casualizado com 3 repetições, sendo a unidade experimental composta de 10 bananas.

A temperatura de armazenamento foi monitorada diariamente com termômetros com bulbo de mercúrio introduzido na polpa de frutos. A temperatura apresentou uma oscilação de $\pm 0,2^{\circ} \mathrm{C}$.

Todos os tratamentos foram submetidos à análise diária das pressões parciais de $\mathrm{O}_{2}$ e $\mathrm{CO}_{2}$, através de analisadores eletrônicos, marca Agri-Datalog. Nos tratamentos em atmosfera controlada (experimento 2) as pressões parciais variavam em função da respiração dos frutos, sendo estas corrigidas diariamente até os níveis preestabelecidos para cada tratamento.
Para a eliminação de etileno, foram utilizados sachês absorventes, marca Allways fresh ${ }^{\circledR}$, à base de permanganato de potássio. Adotou-se um sachê de $10 \mathrm{~g}$ por $2400 \mathrm{~g}$ de fruto para os tratamentos em AM e um sachê por $600 \mathrm{~g}$ de fruto, para os tratamentos em AR e AC. As determinações de etileno foram realizadas a cada três dias por cromatografia gasosa.

Os parâmetros avaliados, em ambos os experimentos, foram índice de cor da epiderme e o índice de escurecimento, segundo metodologia descrita em Chitarra \& Chitarra (1990). O índice de cor da epiderme foi avaliado visualmente comparando as bananas com uma escala variando de 1 a 7 , sendo 1 um fruto totalmente verde e 7 um fruto amarelo com áreas de coloração café. O índice de escurecimento também foi avaliado visualmente comparando os frutos com uma escala de índice de escurecimento variando de 1 a 4, em que 1 é um fruto com até $5 \%$ da superfície com escurecimento, 2 com uma superfície de escurecimento de $6 \%$ até $25 \%, 3$ com $26 \%$ até $50 \%$ da superfície com escurecimento e 4 com mais de $50 \%$ da superfície da epiderme com escurecimento. No experimento 1, também foi avaliada a firmeza de polpa na região mediana do fruto, onde foi previamente retirada a casca. Para esta análise foi utilizado um penetrômetro manual com ponteira de $11 \mathrm{~mm}$ de diâmetro. Os dados foram submetidos à análise de variância e as médias comparadas pelo teste de Duncan ao nível de 5\% de probabilidade de erro.

\section{RESULTADOS E DISCUSSÃO}

No experimento 1, a absorção de etileno resultou em bananas com maior firmeza de polpa e menor escurecimento da casca, porém, a cor da casca ficou mais verde nos frutos armazenados em AM com absorção de etileno do que em AR, também com absorção de etileno (Tabela 1). Possivelmente este resultado esteja relacionado ao efeito da modificação da atmosfera na diminuição na atividade das enzimas clorofilases e sistemas oxidantes, em função do baixo $\mathrm{O}_{2}$ combinado com o alto $\mathrm{CO}_{2}$. Segundo Dilley (1970), em maçãs, o alto $\mathrm{CO}_{2}$ pode bloquear a degradação das clorofilas pelo atraso na síntese protéica, sendo que estas proteínas são enzimas necessárias para a degradação das clorofilas. Brackmann et al. (2000) também observaram, na maçã 'Royal Gala', um retardamento do amarelecimento da casca pelo alto $\mathrm{CO}_{2}$

Houve maior efeito da absorção de etileno sobre a firmeza de polpa do que sobre a cor da casca, o que está de acordo com Oetiker \& Yang (1995), que afirmam que os tecidos da polpa e da casca apresentam resposta 
diferenciada ao etileno. Lobo et al. (2005) também observaram maior firmeza da polpa de bananas com menor concentração de etileno. Possivelmente, a absorção do etileno e o alto $\mathrm{CO}_{2}$ acumulado dentro da embalagem de polietileno, no armazenamento em atmosfera modificada, apresentaram um efeito sinérgico sobre a manutenção da cor da casca da banana 'Prata'. De acordo com Wills et al. (1981), o amarelecimento da casca de frutos pode ser decorrente de diversos fatores, mas principalmente pela ação das clorofilases, sendo que estas enzimas apresentam sua atividade aumentada na presença de etileno (YAMAUCHI et al., 1997).

No experimento 2 verificou-se, em geral, que os tratamentos em AC com absorção de etileno apresentaram cor da casca mais verde e menor escurecimento da casca (Tabelas 2 e 3). Elyatem et al. (1994) e Madrid \& Lopez-Lee (1996) também determinaram um excelente controle da maturação de bananas com o uso de AC.

A absorção do etileno durante o armazenamento refrigerado apresentou melhor resultado sobre a cor e o escurecimento da casca do que o armazenamento em AC sem absorção de etileno (Tabela 2). Este resultado evidencia a grande importância em manter o etileno em baixa concentração no ambiente de armazenamento de bananas. De acordo com Jiang et al. (2004), a duração pós-colheita de bananas está diretamente relacionada à concentração de etileno no ambiente de armazenamento. Lobo et al. (2005) verificaram que quanto maior a concentração de etileno menor é a vida pós-colheita das bananas.
A atmosfera modificada produziu um efeito intermediário entre os tratamentos em $\mathrm{AC}$ e o armazenamento refrigerado, com relação à cor da casca das bananas (Tabela 2). O melhor efeito da atmosfera controlada sobre a cor da casca possivelmente está relacionado à menor concentração de etileno (Tabela 3), visto que nestes tratamentos a relação sachê absorvente/ massa de frutos foi maior, conforme descrito no material e métodos. Este resultado novamente evidencia o pronunciado efeito do etileno sobre o amarelecimento da casca de bananas e está de acordo com o obtido por Lobo et al. (2005), que verificaram que quanto maior a concentração de etileno em que as bananas estão expostas maior será o amarelecimento da casca dos frutos.

Após 28 dias de armazenamento a $12^{\circ} \mathrm{C}$, o tratamento com $21 \mathrm{kPa} \mathrm{O}_{2}+6 \mathrm{kPa}$ de $\mathrm{CO}_{2}$ com absorção de etileno manteve a casca mais verde (Tabela 4). Ao comparar este tratamento com $2,0 \mathrm{kPa} \mathrm{O}_{2}+4,5 \mathrm{kPa} \mathrm{CO}_{2}$ mais absorção de etileno, podese afirmar que o alto $\mathrm{CO}_{2}$ é mais efetivo que o baixo $\mathrm{O}_{2}$ na manutenção da cor verde da casca, durante o armazenamento a $12^{\circ} \mathrm{C}$. Apesar de ter sido realizada a absorção de etileno nestes dois tratamentos, não se consegue eliminar totalmente este gás no ambiente de armazenamento. Assim, como a casca da banana é altamente sensível ao etileno, a presença de $\mathrm{CO}_{2}$, em níveis mais elevados, compete com o fitohormônio pelo seu sítio de ligação no receptor, reduzindo a sua ação sobre os mecanismos de síntese e ação das enzimas responsáveis pela degradação das clorofilas.

TABELA 1 - Qualidade da banana 'Prata' armazenada durante 14 dias a $25^{\circ} \mathrm{C}$. Santa Maria, 2001. (Experimento 1).

\begin{tabular}{|c|c|c|c|}
\hline Tratamentos & Firmeza de polpa $(\mathrm{N})$ & $\begin{array}{l}\text { Índice de cor da } \\
\text { epiderme }^{* * * * * * *}(1-7)\end{array}$ & $\begin{array}{l}\text { Índice de escurecimento da } \\
\text { epiderme }^{* * * * * * * *}(1-4)\end{array}$ \\
\hline $\mathrm{AR}^{* *}$ & $6,21 b^{*}$ & $7,00 \mathrm{a}$ & $4,00 \mathrm{a}$ \\
\hline $\mathrm{AR}+\mathrm{AE}^{* * *}$ & $9,43 \mathrm{a}$ & $5,83 \mathrm{a}$ & $1,13 b$ \\
\hline $\mathrm{AM}^{* * * * *}+\mathrm{AE}$ & $10,51 \mathrm{a}$ & $3,67 \mathrm{~b}$ & $1,00 \mathrm{~b}$ \\
\hline C.V. & 10,40 & 12,23 & 6,52 \\
\hline \multicolumn{4}{|c|}{ 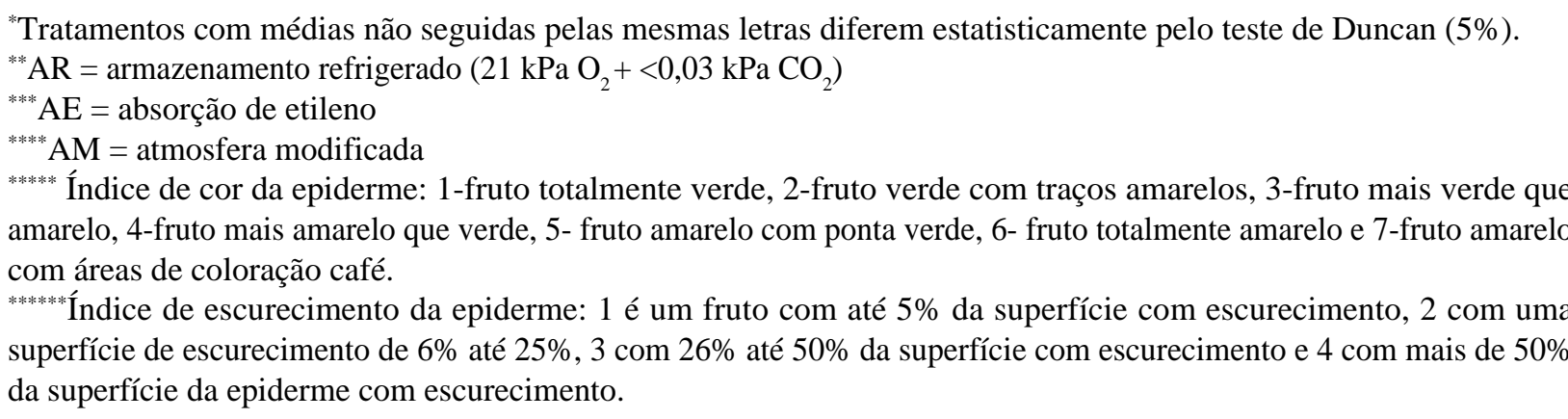 } \\
\hline
\end{tabular}

Ciênc. agrotec., Lavras, v. 30, n. 5, p. 914-919, set./out., 2006 
TABELA 2 - Qualidade da banana 'Prata' armazenada durante 21 dias a $12^{\circ} \mathrm{C}$. Santa Maria, 2001. (Experimento 2).

\begin{tabular}{|c|c|c|c|}
\hline \multirow[b]{2}{*}{ Tratamentos } & \multirow{2}{*}{$\begin{array}{c}21 \text { dias a } 12^{\circ} \mathrm{C} \\
\begin{array}{c}\text { Índice de cor da } \\
\text { epiderme }^{* * * * * * * *}(1-7)\end{array}\end{array}$} & \multicolumn{2}{|c|}{21 dias a $12^{\circ} \mathrm{C}+7$ dias a $25^{\circ} \mathrm{C}$} \\
\hline & & $\begin{array}{c}\text { Índice de cor da } \\
\text { epiderme (1-7) }\end{array}$ & $\begin{array}{l}\text { Índice de escurecimento } \\
\text { da epiderme }{ }^{* * * * * * *}(1-4)\end{array}$ \\
\hline $\mathrm{AR}^{* *}$ & $7,00 a^{*}$ & $7,00 \mathrm{a}$ & $2,25 \mathrm{a}$ \\
\hline $\mathrm{AR}+\mathrm{AE}^{* * *}$ & $3,13 \mathrm{~cd}$ & $7,00 \mathrm{a}$ & $1,40 \mathrm{~b}$ \\
\hline $\mathrm{AM}^{* * * * *}+\mathrm{AE}$ & $3,65 \mathrm{c}$ & $6,67 b$ & $1,88 \mathrm{ab}$ \\
\hline $21 \mathrm{kPa} \mathrm{O}_{2}+3,0 \mathrm{kPa} \mathrm{CO}+\mathrm{AE}$ & $2,50 \mathrm{de}$ & $6,00 \mathrm{c}$ & $1,00 \mathrm{~b}$ \\
\hline $21 \mathrm{kPa} \mathrm{O}_{2}+4,5 \mathrm{kPa} \mathrm{CO} \mathrm{CO}_{2}+\mathrm{AE}$ & $2,25 \mathrm{e}$ & $6,00 \mathrm{c}$ & $1,00 \mathrm{~b}$ \\
\hline $21 \mathrm{kPa} \mathrm{O}_{2}+6,0 \mathrm{kPa} \mathrm{CO} \mathrm{CO}_{2}+\mathrm{AE}$ & $2,00 \mathrm{e}$ & $6,00 \mathrm{c}$ & $1,00 \mathrm{~b}$ \\
\hline $21 \mathrm{kPa} \mathrm{O}{ }_{2}+4,5 \mathrm{kPa} \mathrm{CO} 2$ & $5,00 \mathrm{~b}$ & $7,00 \mathrm{a}$ & $2,25 \mathrm{a}$ \\
\hline $2,0 \mathrm{O}_{2}+4,5 \mathrm{kPa} \mathrm{CO}_{2}+\mathrm{AE}$ & 2,50de & $6,00 \mathrm{c}$ & $1,00 \mathrm{~b}$ \\
\hline C.V. & 13,13 & 1,28 & 18,36 \\
\hline
\end{tabular}

"Tratamentos com médias não seguidas pelas mesmas letras diferem estatisticamente pelo teste de Duncan (5\%).

${ }^{* *} \mathrm{AR}=$ armazenamento refrigerado

**** $\mathrm{AE}=$ absorção de etileno

${ }^{* * * * *} \mathrm{AM}=$ atmosfera modificada

****** Índice de cor da epiderme: 1-fruto totalmente verde, 2-fruto verde com traços amarelos, 3-fruto mais verde que amarelo, 4-fruto mais amarelo que verde, 5- fruto amarelo com ponta verde, 6- fruto totalmente amarelo e 7 -fruto amarelo com áreas de coloração café.

******* Índice de escurecimento da epiderme: 1 é um fruto com até 5\% da superfície com escurecimento, 2 com uma superfície de escurecimento de $6 \%$ até $25 \%, 3$ com $26 \%$ até 50\% da superfície com escurecimento e 4 com mais de 50\% da superfície da epiderme com escurecimento.

TABELA 3 - Concentração média de etileno no ambiente de conservação da banana 'Prata' durante 21 dias a $12^{\circ} \mathrm{C}$ e 14 dias a $25^{\circ} \mathrm{C}$. Santa Maria, 2001.

\begin{tabular}{clc}
\hline $\begin{array}{c}\text { Temperatura de } \\
\text { armazenamento }\end{array}$ & Tratamentos & $\mathbf{C}_{\mathbf{2}} \mathbf{H}_{\mathbf{4}}(\mathbf{p p m})$ \\
\hline & $\mathrm{AR}^{*}$ & 3,92 \\
& $\mathrm{AR}+\mathrm{AE}^{* *}$ & 0,11 \\
& $\mathrm{AM}^{* * *}+\mathrm{AE}$ & 0,80 \\
$12^{\circ} \mathrm{C}$ & $\mathrm{Ar} / 3,0 \mathrm{kPa} \mathrm{CO}+\mathrm{AE}$ & 0,23 \\
& $\mathrm{Ar} / 4,5 \mathrm{kPa} \mathrm{CO}+\mathrm{AE}$ & 0,22 \\
& $\mathrm{Ar} / 6,0 \mathrm{kPa} \mathrm{CO} 2+\mathrm{AE}$ & 0,28 \\
& $\mathrm{Ar} / 4,5 \mathrm{kPa} \mathrm{CO}_{2}$ & 1,22 \\
& $2,0 \mathrm{kPa} \mathrm{O} / 4,5 \mathrm{kPa} \mathrm{CO}_{2}+\mathrm{AE}$ & 0,29 \\
\hline \multirow{2}{*}{$25^{\circ} \mathrm{C}$} & $\mathrm{AR}$ & 17,77 \\
& $\mathrm{AR}+\mathrm{AE}$ & 0,27 \\
\hline & $\mathrm{AM}+\mathrm{AE}$ & 2,44 \\
\hline
\end{tabular}

*AR = armazenamento refrigerado

${ }^{* *} \mathrm{AE}=$ absorção de etileno

${ }^{* * *} \mathrm{AM}=$ atmosfera modificada 
No armazenamento em atmosfera modificada a pressão parcial de $\mathrm{CO}_{2}$ apresentou um rápido aumento dentro da embalagem, principalmente a $25^{\circ} \mathrm{C}$ (Figura 1). Devido à alta taxa respiratória da banana $\left(20,5 \mathrm{~mL}\right.$ de $\mathrm{CO}_{2} \mathrm{~h}^{-1} \mathrm{~kg}^{-1}$ com absorção do etileno e $70,5 \mathrm{~mL}$ de $\mathrm{CO}_{2} \mathrm{~h}^{-1} \mathrm{~kg}^{-1}$ sem absorção de etileno após seis dias a $25^{\circ} \mathrm{C}$ ), as embalagens de polietileno tiveram que sofrer várias microperfurações para evitar que a pressão parcial de $\mathrm{CO}_{2}$ atingisse níveis muito elevados, pois de acordo com Kader (1997), o $\mathrm{CO}_{2}$ acima de 7,0 $\mathrm{kPa}$ pode causar amolecimento do fruto verde e perda de sabor. Porém, no presente trabalho, o $\mathrm{CO}_{2}$ atingiu níveis acima de $14 \mathrm{kPa}$ durante oito dias a $25^{\circ} \mathrm{C}$ sem a ocorrência destes distúrbios (Figura 1). Provavelmente a banana 'Prata' apresenta menor sensibilidade ao $\mathrm{CO}_{2}$. Este resultado evidencia que esta cultivar de banana apresenta um elevado potencial para o armazenamento em atmosfera modificada. De acordo com Kader \& Watkins (2000), o uso da atmosfera modificada é apropriada aos frutos que não apresentam elevada sensibilidade ao $\mathrm{CO}_{2}$.

TABELA 4 - Qualidade da banana 'Prata' armazenada durante 28 dias a $12^{\circ} \mathrm{C}$. Santa Maria, 2001.

\begin{tabular}{|c|c|c|c|}
\hline \multirow[b]{2}{*}{ Tratamentos } & \multirow{2}{*}{$\begin{array}{c}28 \text { dias a } 12^{\circ} \mathrm{C} \\
\begin{array}{c}\text { Índice de cor da } \\
\text { epiderme }\end{array}\end{array}$} & \multicolumn{2}{|c|}{28 dias a $12^{\circ} \mathrm{C}+7$ dias a $25^{\circ} \mathrm{C}$} \\
\hline & & $\begin{array}{c}\text { Índice de cor da } \\
\text { epiderme (1-7) }\end{array}$ & $\begin{array}{l}\text { Índice de escurecimento } \\
\text { da epiderme } e^{* * * * * * * *}(1-4)\end{array}$ \\
\hline $\mathrm{AR}^{* *}$ & - & - & - \\
\hline $\mathrm{AR}+\mathrm{AE}^{* * *}$ & - & - & - \\
\hline $\mathrm{AM}^{* * * * *}+\mathrm{AE}$ & - & - & - \\
\hline $21 \mathrm{kPa} \mathrm{O}_{2}+3,0 \mathrm{kPaCO} \mathrm{CO}_{2}+\mathrm{AE}$ & $3,00 \mathrm{~b} *$ & $6,00 \mathrm{~b}$ & $1,25 b$ \\
\hline $21 \mathrm{kPa} \mathrm{O}+4,5 \mathrm{kPaCO} \mathrm{CO}_{2}+\mathrm{AE}$ & $3,25 b$ & $6,25 b$ & $1,00 \mathrm{~b}$ \\
\hline $21 \mathrm{kPa} \mathrm{O}+6,0 \mathrm{kPaCO} \mathrm{CO}_{2}+\mathrm{AE}$ & $2,00 \mathrm{c}$ & $6,00 \mathrm{~b}$ & $1,00 \mathrm{~b}$ \\
\hline $21 \mathrm{kPa} \mathrm{O}+4,5 \mathrm{kPa} \mathrm{CO} 2$ & $5,00 \mathrm{a}$ & $7,00 \mathrm{a}$ & $4,00 \mathrm{a}$ \\
\hline $2,0 \mathrm{kPa} \mathrm{O} / 4,5 \mathrm{kPa} \mathrm{CO}+\mathrm{AE}$ & $3,00 \mathrm{~b}$ & $6,00 \mathrm{~b}$ & $1,00 \mathrm{~b}$ \\
\hline C.V. & 7,33 & 3,58 & 13,55 \\
\hline
\end{tabular}

*Tratamentos com médias não seguidas pelas mesmas letras diferem estatisticamente pelo teste de Duncan (5\%).

${ }^{* *} \mathrm{AR}=$ armazenamento refrigerado $\left(21 \mathrm{kPa} \mathrm{O}_{2}+<0,03 \mathrm{kPa} \mathrm{CO}_{2}\right)$

*** $\mathrm{AE}=$ absorção de etileno

**** $\mathrm{AM}=$ atmosfera modificada

***** Índice de cor da epiderme: 1-fruto totalmente verde, 2-fruto verde com traços amarelos, 3-fruto mais verde que amarelo, 4-fruto mais amarelo que verde, 5- fruto amarelo com ponta verde, 6- fruto totalmente amarelo e 7-fruto amarelo com áreas de coloração café.

****** Índice de escurecimento da epiderme: 1 é um fruto com até 5\% da superfície com escurecimento, 2 com uma superfície de escurecimento de $6 \%$ até $25 \%, 3$ com $26 \%$ até $50 \%$ da superfície com escurecimento e 4 com mais de $50 \%$ da superfície da epiderme com escurecimento.

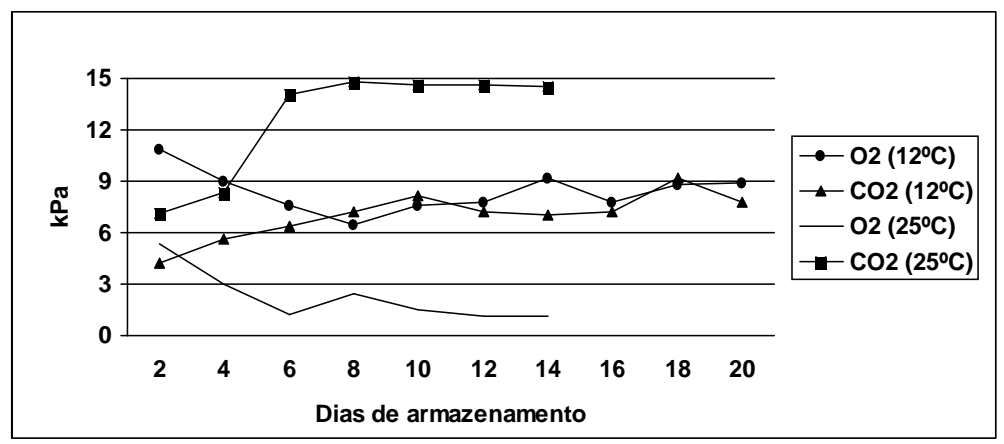

FIGURA 1 - Pressões parciais de $\mathrm{O}_{2}$ e $\mathrm{CO}_{2}$ nas embalagens de polietileno contendo bananas 'Prata' e com absorção de etileno. Santa Maria, 2001. (Experimento 2).

Ciênc. agrotec., Lavras, v. 30, n. 5, p. 914-919, set./out., 2006 


\section{CONCLUSÃO}

A absorção do etileno mantém uma melhor qualidade da banana 'Prata', tanto no armazenamento a $25^{\circ} \mathrm{C}$ como a $12^{\circ} \mathrm{C}$, sendo o principal fator responsável pelo amadurecimento de bananas, porém seu efeito é melhorado na presença do alto $\mathrm{CO}_{2}$ em atmosfera controlada ou atmosfera modificada. A banana 'Prata' pode ser armazenada em atmosfera modificada durante 14 e 21 dias, a $25^{\circ} \mathrm{C}$ e $12^{\circ} \mathrm{C}$, respectivamente, e por 28 dias em atmosfera controlada a $12^{\circ} \mathrm{C}$, sempre com absorção do etileno.

\section{REFERÊNCIAS BIBLIOGRÁFICAS}

ANTONIALI, S.; DURIGAN, J. F.; KANESIRO, M. A. B.; MARQUES, M. O.; TOSTES, D. R. D. Conservação póscolheita de banana 'Nanicão' associando-se a embalagem em saco plástico contendo $\mathrm{KMnO}_{4}$ com refrigeração. In: CONGRESSO BRASILEIRO DE FRUTICULTURA, 14., 1996, Curitiba. Anais... Curitiba: SBF, 1996. v. 1, p. 93.

BRACKMANN, A.; STEFFENS, C. A.; HUNSCHE, M. Armazenamento de maçã cv. Royal Gala em atmosfera controlada com alta pressão parcial de $\mathrm{CO}_{2}$. Revista Brasileira de Armazenamento, Viçosa, v. 25, n. 2, p. 3-8, 2000.

Chitarra, M. I. F.; CHITARRA, A. B. Pós-colheita de frutos e hortaliças. Lavras: Faepe, 1990. 543 p.

DILLEY, D. R. Constituents of fruits: enzymes. In: HULME, A. C. (Ed.). Biochemistry of fruits and their products. London: Academic, 1970. p. 179-207.

ELYATEM, S. M.; BANKS, N. H.; CAMERON, A. C. Oxygen concentrations effects on ethylene production by ripenning banana tissue. Postharvest Biology and Technology, Amsterdam, v. 4, p. 343-351, 1994.

JIANG, Y.; JOYCE, D. C.; MACNISH, A. J. Extension of the shelf life of banana fruit by 1-methylcyclopropene in combination with polyethylene bags. Postharvest Biology and Technology, Amsterdam, v. 16, p. 187-193, 1999.
JIANG, W.; ZHANG, M.; HE, J.; ZHOU, L. Regulation of 1MCP-treated banana fruit quality by exogenous ethylene and temperature. Food Science and Technology International, London, v. 10, n. 1, p. 15-20, 2004.

KADER, A. A. A summary of CA requirements and recommendations for fruits other than apples and pears. In: INTERNATIONAL CONTROLLED ATMOSPHERE RESEARCH CONFERENCE, 7., 1997, Davis. Proceedings... Davis: [s.n.], 1997. v. 3, p. 1-34.

KADER, A. A.; WATKINS, C. B. Modified atmosphere packaging: toward 2000 and beyond. HortTechnology, Alexandria, v. 10, n. 3, p. 483-486, 2000.

LOBO, M. G.; GONZALES, M.; PENA, A.; MARRERO, A. Effects of ethylene exposure temperature on shelf life, composition and quality of artificially ripened bananas (Musa acuminata AAA, cv. 'Dwarf Cavendish'). Food Science and Technology International, London, v. 11, n. 2, p. 99-105, 2005.

MADRID, M.; LOPEZ-LEE, F. Differences in ripening characteristics of controlled atmosphere or air-stored bananas. Acta Horticulturae, Leuven, n. 464, p. 357362, 1996.

OETIKER, J. H.; YANG, S. F. The role of ethylene in fruit ripening. Acta Horticulturae, Leuven, n. 368, p. 167-178, 1995.

WILLS, R. H. H.; LEE, T. H.; GRAHAM, D.; McGLASSON, W. B.; HALL, E. G. Postharvest: an introduction to the physiology and handling of fruit and vegetables. London: Granada, 1981. 163 p.

YAMAUCHI, N.; AKIYAMA, Y.; KAKO, S.; HASHINAGA, F. Chlorophyll degradation in Wase satsuma mandarin (Citrus unshiu Marc.) fruit with on-tree maturation and ethylene treatment. Scientia Horticulturae, Amsterdam, v. 71, n. 3, p. 35-42, 1997. 